Guido J. Reiss*, Michaela K. Meyer and Jürgen Graf

\title{
Synthesis and crystal structure of a new polymorph of diisopropylammonium trichloroacetate, $\mathrm{C}_{8} \mathrm{H}_{16} \mathrm{Cl}_{3} \mathrm{NO}_{2}$
}

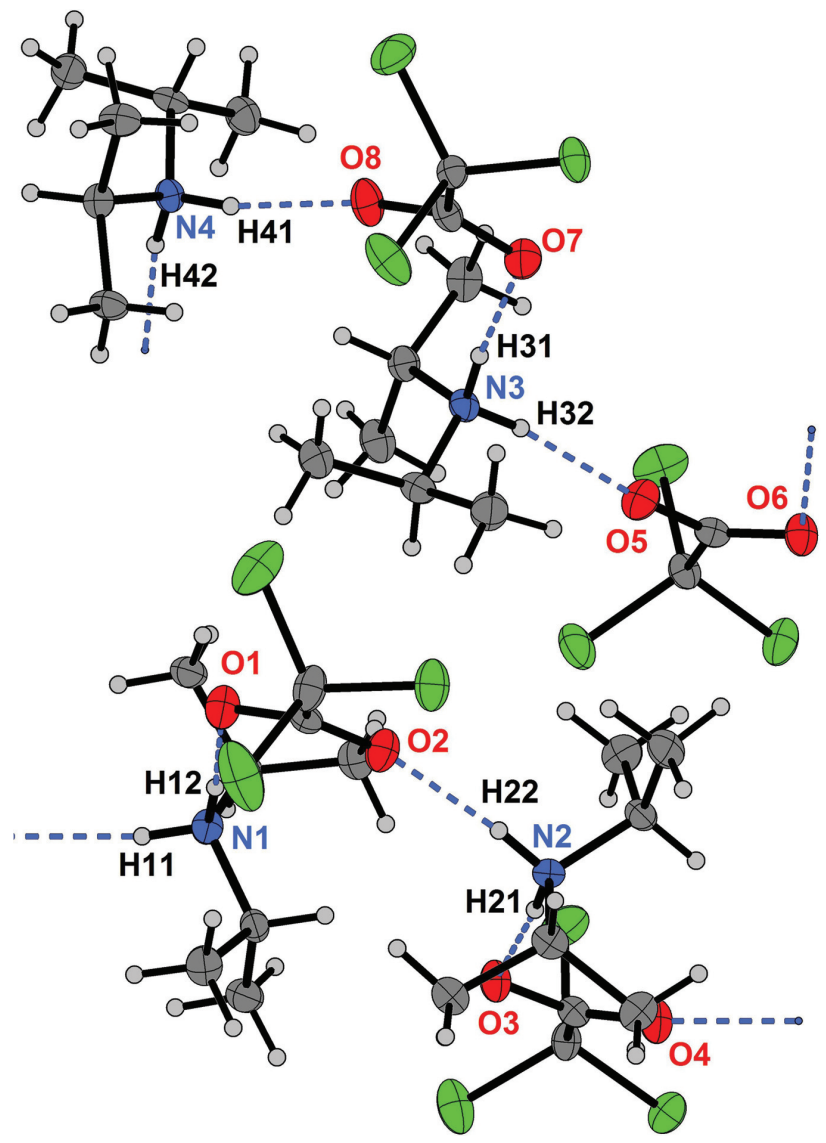

https://doi.org/10.1515/ncrs-2019-0064

Received January 20, 2019; accepted March 9, 2019; available online July 20, 2019

\footnotetext{
*Corresponding author: Guido J. Reiss, Institut für Anorganische Chemie und Strukturchemie, Lehrstuhl II: Material- und Strukturforschung, Heinrich-Heine-Universität Düsseldorf, Universitätsstrasse 1, D-40225 Düsseldorf, Germany, e-mail: reissg@hhu.de

Michaela K. Meyer: Institut für Anorganische Chemie und Strukturchemie, Lehrstuhl II: Material- und Strukturforschung, Heinrich-Heine-Universität Düsseldorf, Universitätsstrasse 1, D-40225 Düsseldorf, Germany

Jürgen Graf: Incoatec GmbH, Max-Planck-Strasse 2, D-21502 Geesthacht, Germany
}

\begin{abstract}
$\mathrm{C}_{8} \mathrm{H}_{16} \mathrm{Cl}_{3} \mathrm{NO}_{2}$, monoclinic, $P 2_{1}$ (no. 4), $a=9.1804(5)$ ), $b=19.4133(10) \AA, \quad c=13.9191(7) \AA, \quad \beta=90.593(3)^{\circ}$, $V=2480.6(2) \AA^{3}, Z=8, R_{\mathrm{gt}}(F)=0.0605, w R_{\text {ref }}\left(F^{2}\right)=0.1387$, $T=296(2) \mathrm{K}$.
\end{abstract}

CCDC no.: 1902131

Table 1: Data collection and handling.

\begin{tabular}{ll}
\hline Crystal: & Needle, colorless \\
Size: & $0.51 \times 0.12 \times 0.05 \mathrm{~mm}$ \\
Wavelength: & Mo $K \alpha$ radiation $(0.71073 \AA$ A) \\
$\mu:$ & $0.72 \mathrm{~mm}^{-1}$ \\
Diffractometer, scan mode: & Bruker APEX-II, $\varphi$ and $\omega$-scans \\
$\theta_{\max }$, completeness: & $29^{\circ},>99 \%$ \\
$N(h k l)_{\text {measured }}, N\left(h k l l_{\text {unique }}, R_{\text {int }}:\right.$ & $56285,13160,0.064$ \\
Criterion for $I_{\text {obs }}, N(h k l)_{\text {gt }}:$ & $I_{\text {obs }}>2 \sigma\left(I_{\text {obs }}\right), 11276$ \\
$N(\text { param })_{\text {refined }}:$ & 521 \\
Programs: & DIAMOND [1], Bruker programs \\
& [2], SHELX [3, 4] \\
\hline
\end{tabular}

The asymmetric unit of the title crystal structure is shown in the figure. Ellipsoids are drawn at the 50\% probability level [1]. Tables 1 and 2 contain details on the crystal structure and measurement conditions and a list of the atoms including atomic coordinates and displacement parameters.

\section{Source of the material}

In a typical experiment $0.50 \mathrm{~g}(3.06 \mathrm{mmol})$ trichloroacetic acid and $0.30 \mathrm{~g}$ (3.00 mmol) diisopropylamine (dip) were mixed in a petri dish. The mixture emits a white smoke. After a few days two types of colourless crystals (cubes and needles) form in the solution. Recrystallization from ethanol yields cube crystals only, whereas the needle crystals were obtained from an 2-propanol solution. Preliminary X-ray experiments showed that the cubes represent an orthorhombic phase, whereas the needle crystals show monoclinic symmetry. The IR and Raman spectra show the typical bands and signals for the diisopropylammonium $(\operatorname{dip} \mathrm{H})$ cation [5] and the trichloroacetate (TCA) anion [6].

The Raman spectrum was measured using a Bruker MULTIRAM spectrometer; Nd:YAG-Laser at $1064 \mathrm{~nm}$; 
Table 2: Fractional atomic coordinates and isotropic or equivalent isotropic displacement parameters $\left(\AA^{2}\right)$.

\begin{tabular}{|c|c|c|}
\hline Atom & $x$ & $y$ \\
\hline $\mathrm{Cl} 1$ & $-0.0416(2)$ & $0.74558(11)$ \\
\hline $\mathrm{Cl} 2$ & $-0.1031(2)$ & $0.72644(10)$ \\
\hline $\mathrm{Cl} 3$ & $0.19028(18)$ & $0.74415(9)$ \\
\hline $\mathrm{Cl} 4$ & $0.48392(19)$ & $0.31158(9)$ \\
\hline $\mathrm{Cl} 5$ & $0.70476(16)$ & $0.31718(8)$ \\
\hline $\mathrm{Cl} 6$ & $0.40384(19)$ & $0.32273(9)$ \\
\hline $\mathrm{Cl} 7$ & $0.38638(19)$ & $0.34106(10)$ \\
\hline $\mathrm{Cl} 8$ & $0.67175(17)$ & $0.30574(9)$ \\
\hline $\mathrm{Cl9}$ & $0.4305(2)$ & $0.30275(9)$ \\
\hline $\mathrm{Cl} 10$ & $-0.0458(2)$ & $0.74599(9)$ \\
\hline $\mathrm{Cl} 11$ & $0.17593(16)$ & $0.73766(8)$ \\
\hline $\mathrm{Cl} 12$ & $-0.1222(2)$ & $0.71626(11)$ \\
\hline 01 & $-0.0930(5)$ & $0.5990(2)$ \\
\hline 02 & $0.1496(5)$ & $0.6018(3)$ \\
\hline 03 & $0.4064(5)$ & $0.4546(2)$ \\
\hline 04 & $0.6490(5)$ & $0.4564(2)$ \\
\hline 05 & $0.4136(5)$ & $0.4573(2)$ \\
\hline 06 & $0.6542(5)$ & $0.4419(2)$ \\
\hline 07 & $0.1464(5)$ & $0.6025(2)$ \\
\hline 08 & $-0.0960(5)$ & $0.5935(3)$ \\
\hline N1 & $-0.0632(5)$ & $0.4731(3)$ \\
\hline H11 & -0.150574 & 0.465323 \\
\hline $\mathrm{H} 12$ & -0.068586 & 0.512666 \\
\hline $\mathrm{N} 2$ & $0.4350(5)$ & $0.5822(3)$ \\
\hline $\mathrm{H} 21$ & 0.431481 & 0.542184 \\
\hline $\mathrm{H} 22$ & 0.347104 & 0.589479 \\
\hline N3 & $0.1257(5)$ & $0.4979(3)$ \\
\hline H31 & 0.126573 & 0.530349 \\
\hline H32 & 0.215037 & 0.480215 \\
\hline N4 & $-0.3762(5)$ & $0.5492(3)$ \\
\hline H41 & -0.286179 & 0.565930 \\
\hline $\mathrm{H} 42$ & -0.375421 & 0.516328 \\
\hline $\mathrm{C} 1$ & $0.0437(7)$ & $0.4824(3)$ \\
\hline $\mathrm{H} 1 \mathrm{~A}$ & 0.138835 & 0.494873 \\
\hline $\mathrm{C} 2$ & $-0.0121(7)$ & $0.5423(3)$ \\
\hline $\mathrm{H} 2 \mathrm{~A}$ & -0.106087 & 0.530858 \\
\hline $\mathrm{H} 2 \mathrm{~B}$ & -0.020012 & 0.582840 \\
\hline $\mathrm{H} 2 \mathrm{C}$ & 0.054655 & 0.550749 \\
\hline C $3 \mathrm{~A}$ & $0.0596(7)$ & $0.4173(4)$ \\
\hline $\mathrm{H} 3 \mathrm{~A}$ & -0.032501 & 0.405386 \\
\hline H3B & 0.130252 & 0.424129 \\
\hline $\mathrm{H} 3 \mathrm{C}$ & 0.091292 & 0.380811 \\
\hline $\mathrm{C} 4$ & $-0.0328(7)$ & $0.4166(3)$ \\
\hline $\mathrm{H} 4 \mathrm{~A}$ & -0.041102 & 0.372094 \\
\hline $\mathrm{C} 5$ & $-0.1517(7)$ & $0.4211(4)$ \\
\hline $\mathrm{H} 5 \mathrm{~A}$ & -0.147518 & 0.465336 \\
\hline $\mathrm{H} 5 \mathrm{~B}$ & -0.245263 & 0.415234 \\
\hline $\mathrm{H} 5 \mathrm{C}$ & -0.136994 & 0.385586 \\
\hline C6 & $0.1192(7)$ & $0.4232(3)$ \\
\hline $\mathrm{H} 6 \mathrm{~A}$ & 0.132037 & 0.468534 \\
\hline H6B & 0.133466 & 0.389511 \\
\hline $\mathrm{H} 6 \mathrm{C}$ & 0.188832 & 0.415928 \\
\hline $\mathrm{C} 7$ & $0.0289(7)$ & $0.6272(3)$ \\
\hline $\mathrm{C} 8$ & $0.0201(7)$ & $0.7070(3)$ \\
\hline $\mathrm{C} 9$ & $0.5408(7)$ & $0.5750(3)$ \\
\hline
\end{tabular}

Table 2 (continued)

\begin{tabular}{|c|c|c|c|c|}
\hline Atom & $x$ & $y$ & $z$ & $U_{\text {iso }} * / U_{\text {eq }}$ \\
\hline H9A & 0.637591 & 0.564877 & 0.309888 & $0.024^{\star}$ \\
\hline C10 & $0.4906(8)$ & $0.5144(4)$ & $0.2212(5)$ & $0.0277(14)$ \\
\hline $\mathrm{H} 10 \mathrm{~A}$ & 0.490368 & 0.473194 & 0.259332 & $0.042^{\star}$ \\
\hline $\mathrm{H} 10 \mathrm{~B}$ & 0.555907 & 0.508779 & 0.168382 & $0.042^{*}$ \\
\hline $\mathrm{H} 10 \mathrm{C}$ & 0.394070 & 0.523177 & 0.197099 & $0.042^{*}$ \\
\hline C11 & $0.5476(8)$ & $0.6413(4)$ & $0.2259(5)$ & $.0287(15)$ \\
\hline $\mathrm{H} 11 \mathrm{~A}$ & 0.451188 & 0.654091 & 0.205356 & $0.043^{*}$ \\
\hline H11B & 0.607905 & 0.634700 & 0.170779 & $0.043^{*}$ \\
\hline $\mathrm{H} 11 \mathrm{C}$ & 0.587986 & 0.677200 & 0.265505 & $0.043^{*}$ \\
\hline C12 & $0.4637(7)$ & $0.6381(3)$ & $0.4364(4)$ & $0.0208(12)$ \\
\hline $\mathrm{H} 12 \mathrm{~A}$ & 0.453061 & 0.682893 & 0.404715 & $0.025^{\star}$ \\
\hline C13 & $0.6167(7)$ & $0.6328(4)$ & $0.4780(5)$ & $0.0263(14)$ \\
\hline $\mathrm{H} 13 \mathrm{~A}$ & 0.629964 & 0.588359 & 0.506945 & $0.039^{*}$ \\
\hline H13B & 0.630808 & 0.667989 & 0.525659 & $0.039 *$ \\
\hline $\mathrm{H} 13 \mathrm{C}$ & 0.686237 & 0.638802 & 0.427592 & $0.039^{*}$ \\
\hline C14 & $0.3457(7)$ & $0.6314(3)$ & $0.5127(5)$ & $0.0243(13)$ \\
\hline $\mathrm{H} 14 \mathrm{~A}$ & 0.251382 & 0.633708 & 0.482487 & $0.037^{\star}$ \\
\hline H14B & 0.355499 & 0.668312 & 0.558301 & $0.037^{\star}$ \\
\hline $\mathrm{H} 14 \mathrm{C}$ & 0.356203 & 0.588099 & 0.545324 & $0.037^{\star}$ \\
\hline C15 & $0.5299(6)$ & $0.4295(3)$ & $0.4608(4)$ & $0.0169(11)$ \\
\hline C16 & $0.5327(6)$ & $0.3481(3)$ & 0.47 & $0.0210(12)$ \\
\hline C17 & $0.0941(7)$ & $0.5324(3)$ & $0.0280(4)$ & $0.0216(13)$ \\
\hline $\mathrm{H} 17 \mathrm{~A}$ & 0.110305 & 0.498831 & 0.079549 & $0.026^{*}$ \\
\hline C18 & $-0.0624(7)$ & $0.5565(4)$ & $0.0316(5)$ & $0.0300(15)$ \\
\hline $\mathrm{H} 18 \mathrm{~A}$ & -0.085286 & 0.570166 & 0.095948 & $0.045^{\star}$ \\
\hline $\mathrm{H} 18 \mathrm{~B}$ & -0.125806 & 0.519603 & 0.012020 & $0.045^{\star}$ \\
\hline $\mathrm{H} 18 \mathrm{C}$ & -0.075593 & 0.594948 & -0.010987 & $0.045^{\star}$ \\
\hline C19 & $0.2026(7)$ & $0.5911(4)$ & $0.0408(5)$ & $0.0288(15)$ \\
\hline $\mathrm{H} 19 \mathrm{~A}$ & 0.188324 & 0.624334 & -0.009563 & $0.043^{*}$ \\
\hline H19B & 0.299959 & 0.573285 & 0.038049 & $0.043^{*}$ \\
\hline $\mathrm{H} 19 \mathrm{C}$ & 0.187768 & 0.612782 & 0.101901 & $0.043^{*}$ \\
\hline C20 & $0.0248(7)$ & $0.4423(3)$ & $-0.1001(4)$ & $0.0216(13)$ \\
\hline $\mathrm{H} 20 \mathrm{~A}$ & -0.073546 & 0.461530 & -0.106559 & $0.026^{\star}$ \\
\hline $\mathrm{C} 21$ & $0.0759(7)$ & $0.4188(3)$ & $-0.1991(5)$ & $0.0261(14)$ \\
\hline $\mathrm{H} 21 \mathrm{~A}$ & 0.084891 & 0.458133 & -0.240509 & $0.039 *$ \\
\hline H21B & 0.006228 & 0.387262 & -0.226115 & $0.039 *$ \\
\hline $\mathrm{H} 21 \mathrm{C}$ & 0.168733 & 0.396421 & -0.192829 & $0.039^{*}$ \\
\hline C22 & $0.0205(8)$ & $0.3826(3)$ & $-0.0306(5)$ & $0.0271(14)$ \\
\hline $\mathrm{H} 22 \mathrm{~A}$ & 0.117748 & 0.366222 & -0.018742 & $0.041^{\star}$ \\
\hline $\mathrm{H} 22 \mathrm{~B}$ & -0.037362 & 0.346069 & -0.057618 & $0.041^{\star}$ \\
\hline $\mathrm{H} 22 \mathrm{C}$ & -0.021560 & 0.397435 & 0.028769 & $0.041^{*}$ \\
\hline $\mathrm{C} 23$ & $0.5283(7)$ & $0.4234(3)$ & $-0.0264(4)$ & $0.0185(12)$ \\
\hline C24 & $0.5067(7)$ & $0.3470(3)$ & $0.0044(4)$ & $0.0203(12)$ \\
\hline C25 & $-0.4132(7)$ & $0.5164(3)$ & $-0.2728(4)$ & $0.0191(12)$ \\
\hline $\mathrm{H} 25 \mathrm{~A}$ & -0.399566 & 0.550728 & -0.323549 & $0.023^{*}$ \\
\hline C26 & $-0.5681(7)$ & $0.4915(4)$ & $-0.2774(5)$ & $0.0248(13)$ \\
\hline $\mathrm{H} 26 \mathrm{~A}$ & -0.589773 & 0.466219 & -0.219971 & $0.037^{*}$ \\
\hline H26B & -0.580948 & 0.462058 & -0.332238 & $0.037^{\star}$ \\
\hline $\mathrm{H} 26 \mathrm{C}$ & -0.632592 & 0.530252 & -0.282805 & $0.037^{\star}$ \\
\hline C27 & $-0.3039(7)$ & $0.4587(4)$ & $-0.2873(5)$ & $0.0267(14)$ \\
\hline $\mathrm{H} 27 \mathrm{~A}$ & -0.206900 & 0.477091 & -0.283993 & $0.040^{*}$ \\
\hline H27B & -0.320011 & 0.437862 & -0.349002 & $0.040^{*}$ \\
\hline $\mathrm{H} 27 \mathrm{C}$ & -0.315667 & 0.424672 & -0.237895 & $0.040^{*}$ \\
\hline $\mathrm{C} 28$ & $-0.4748(7)$ & $0.6060(3)$ & $-0.1443(4)$ & $0.0190(12)$ \\
\hline $\mathrm{H} 28 \mathrm{~A}$ & -0.573531 & 0.587656 & -0.137251 & $0.023^{*}$ \\
\hline C29 & $-0.4787(8)$ & $0.6648(3)$ & $-0.2161(5)$ & $0.0250(14)$ \\
\hline
\end{tabular}


Table 2 (continued)

\begin{tabular}{lrrrr}
\hline Atom & $\boldsymbol{x}$ & $\boldsymbol{y}$ & $\boldsymbol{z}$ & $\boldsymbol{U}_{\text {iso }}{ }^{*} / \boldsymbol{U}_{\text {eq }}$ \\
\hline H29A & -0.381170 & 0.679821 & -0.228696 & $0.038^{*}$ \\
H29B & -0.533880 & 0.702328 & -0.190291 & $0.038^{*}$ \\
H29C & -0.523629 & 0.649277 & -0.274865 & $0.038^{*}$ \\
C30 & $-0.4182(7)$ & $0.6296(4)$ & $-0.0455(4)$ & $0.0238(13)$ \\
H30A & -0.410404 & 0.590544 & -0.003480 & $0.036^{*}$ \\
H30B & -0.484580 & 0.662488 & -0.018927 & $0.036^{*}$ \\
H30C & -0.324062 & 0.650480 & -0.052432 & $0.036^{*}$ \\
C31 & $0.0208(7)$ & $0.6246(3)$ & $-0.2215(4)$ & $0.0200(12)$ \\
C32 & $0.0096(7)$ & $0.7026(3)$ & $-0.2483(4)$ & $0.0190(12)$ \\
\hline
\end{tabular}

RT-InGaAS-detector; $4000-70 \mathrm{~cm}^{-1}$ : 3062(w), 2986(v(CH), s), 2962(s), 2940(v(C-H), vs), 2745(w), 2492(w), $1678\left(v_{\text {as }}\left(\mathrm{COO}^{-}\right), \mathrm{m}\right), 1456(\delta(\mathrm{C}-\mathrm{H}), \mathrm{m}), 1428(\delta(\mathrm{C}-\mathrm{H}), \mathrm{m})$, 1322( $v_{\text {sym. }}$ COO-, m), 1181(w), 1099(w), $954(\mathrm{w}), 912(\mathrm{w})$, 832(m), 804(s), 733( $\left.\left(\mathrm{COO}^{-}\right), \mathrm{m}\right), 670(\mathrm{~m}), 471(\mathrm{~m}), 443(\mathrm{~s})$, 422( $\mathrm{COO}^{-}$, vs $) 318,275\left(\delta_{\mathrm{as}}\left(\mathrm{CCl}_{3}\right), \mathrm{s}\right), 194\left(\rho_{\mathrm{s}}\left(\mathrm{CCl}_{3}\right), \mathrm{s}\right)$, 119(w). IR data collected on a Digilab FT3400 spectrometer using a MIRacle ATR unit (Pike Technologies); 4000-560 cm ${ }^{-1}$ : 3062( $\left.\left(\mathrm{CH}_{3}\right), \mathrm{s}\right), 2985(\mathrm{v}(\mathrm{C}-\mathrm{H}), \mathrm{s})$, 2946(m), 2890(m), 2694(m), 2585(w), 2498(m), 2446(w), $1657\left(v_{\text {as }}\left(\mathrm{COO}^{-}\right), \mathrm{vs}\right), 1615(\mathrm{sh}), 1504(\mathrm{w}), 1464(\mathrm{w}), 1399(\mathrm{~m})$, 1380(w), 1354(m), 1319(( $\left.\mathrm{v}_{\mathrm{s}}\left(\mathrm{COO}^{-}\right), \mathrm{vs}\right), 1149(\mathrm{~m}), 1102(\mathrm{~m})$, 823( $v_{\mathrm{as}}\left(\mathrm{CCl}_{3}, \mathrm{~s}\right), \quad 735\left(\delta_{\mathrm{a}}\left(\mathrm{COO}^{-}\right), \mathrm{s}\right), \quad 673(\mathrm{~m}) \quad\{\mathrm{w}=$ weak, $\mathrm{m}=$ medium, $\mathrm{s}=$ strong, $\mathrm{vs}=$ very strong $\}$.

\section{Experimental details}

The data collection followed the standard procedures of the APEX2 user interface. For data integration and reduction a strategy using the narrow frame algorithm for 3D profile modelling was applied [2]. Structure solution and completion of the structural model was performed using the SHELX software package [3, 4]. Hydrogen atoms were included in last stages of refinement using a riding model with constrained $U_{\text {iso }}$ parameters [4]. It should be noted that the Flack parameter determined using 4522 Parsons' quotients [7] was 0.12(2) for this $\mathrm{Cl}$-containing structure measured using Mo radiation. Despite significant deviation from zero, no inversion twin was refined.

\section{Comment}

Some simple diisopropylammonium $(\operatorname{dip} \mathrm{H})$ salts have attracted attention as ferroelectric materials [8-13]. The aforementioned studies almost exclusively focused on some of the corresponding halogenides. Newer developments point to $\operatorname{dip} \mathrm{H}$ salts based on oxygen-containing counter anions like perchlorate $[14,15]$ or trifluormethylsulfonate to provide interesting physical properties [16]. For the dipH perchlorate [17], as well as for the methanesulfonate [5], we have presented some basic structural features many years ago. Generally, the structural chemistry of simple dipH salts dates back in the ninetys of the last century [18]. The dipH halogenides and some other directly related salt structures, which were characterized, all feature hydrogen bonded chains [19-27]. Even though the physical properties associated with temperature depending phase transitions have only been recently reported, the fact that this class of compounds exhibits polymorphism for almost each compound has been shown earlier. \{chloride: [18, 20]; bromide: [22, 23]; iodide [24, 25]\}. Furthermore, $\operatorname{dip} \mathrm{H}$ salts are able to incorporate various solvent molecules [26-28]. This contribution forms part of our longstanding interest in hydrogen-bonded $\operatorname{dip} \mathrm{H}$ halogenides and pseudo halogenide $[19,22,24,26]$, dipH salts with oxygencontaining counter anions [5, 17, 29] and a limited number of $\operatorname{dip} \mathrm{H}$ halogenidometallates [30, 31]. Furthermore, hydrogenbonded trichloroacetate salts are also materials with interesting properties [32-34]. Many of the chain-type hydrogen bonded polymers like $\operatorname{dip} \mathrm{HI}, \operatorname{dip} \mathrm{HCl}$, dip $\mathrm{HBr}$, dip $\mathrm{H}\left[\mathrm{HF}_{2}\right]$ etc. crystallize in the space group $P 2{ }_{1} 2_{1} 2_{1}$. In these structures hydrogen-bonded chains run along two crystallographically axes and thus are perpendicular to each other. Form a structural point of view the already reported structure of diisopropylammmonium trichloroacetate (dipH TCA) exactly features such hydrogen-bonded, perpendicularily crossed chains [35].

We here report a second polymorph of $\operatorname{dipH}$ TCA. The asymmetric unit contains four crystallographically independent $\operatorname{dip} \mathrm{H}$ cations and four TCA counter anions ( $c f$. the figure). Similarly to other dipH salts, hydrogen-bonded chains of cations and anions are formed. The $\mathrm{N}$... O distances within these hydrogen bonds fall in the narrow range of 2.777(7)-2.811(7) A. The graph set descriptor for the hydrogen bonding motif in the title structure is $\mathrm{C}_{2}^{2}(6)$ [36]. Anions and cations are both ordered and their geometric parameters are all in the expected ranges. The isopropyl groups are individually rotated around the $\mathrm{C}-\mathrm{N}$ bonds to fill the needs of packing, which is typical for the dipH salts.

To verify that the $Z^{\prime}=4$ situation is true we furthermore analyzed some key features of the title structure. In detail, the two crystalllographically independent chains (chain 1: N1, N2, O1-O4; chain 2: N3, N4, O5-O8) feature significantly different geometries ( $c f$. figure [1]). For example the $\mathrm{N} \cdot \mathrm{N}$ distances in chain 1 are 5.059(7) and 5.082(7) $\AA$, whereas the corresponding distances are 4.944(7) and 4.941(7) $\AA$ in chain 2 . The same is true for the $\mathrm{N} \cdots \mathrm{N} \cdots \mathrm{N}$ angles [chain 1: 129.7(1) ${ }^{\circ}$; chain 2: $\left.136.5(1)^{\circ}\right]$. We had proposed that the general rules of hydrocarbon chain packing [37] can be retrieved sometime in the packing of a dipH salt [17]. Obviously, in the case of the title structure, optimization procedures during the crystallization process lead to a packing with $Z^{\prime}=4$. 
The comparison of the asymmetric unit of the title structure with the orthorhombic polymorph 1 shows that the content is doubled. Another obvious difference of the title structure compared to the orthorhombic polymorph 1 of dipH TCA [34] is that in the polymorph 1 one crystallographically independent TCA anion shows disorder of the $\mathrm{CCl}_{3}$ group, whereas the other one appears ordered. The most interesting observation is, that the hydrogen bonded chains run both along the crystallographic $a$ direction in the title structure which is in glaring contrast to polymorph 1 in which the chains run along two directions, which are perpendicular to each other.

A solid-state phase transition between the orthorhombic polymorph 1 and the new monoclinic polymorph 2 seems unlikely given the fact that it would require a complete structural rearrangement, as the arrangement of crossed chains in 1 will not be reorganized to the parallel arrangement found in the title structure. However, it may be of interest to set up an advanced study to investigate the potential temperature and pressure dependence of structural changes for both polymorphs. Finally, it was surprising to us that in the case of dipH TCA two chain type structures are observed, whereas in the case of $\operatorname{dipH}$ trifluoroacetate and the corresponding pentafluoropropionate [29] as well as acetates with bulkier substituents [38, 39], hydrogen-bonded cyclic moieties, composed of two cations and two anions, are observed.

Acknowledgements: We gratefully acknowledge support by the Ministry of Innovation, Science and Research of NorthRhine Westphalia and the German Research Foundation (DFG) for financial support (Bruker diffractometer, APEX2Dual Source; INST 208/589-1, project No. 208167569). Funding by the open access fund of the Heinrich-Heine-Universiät Düsseldorf is gratefully acknowledged.

\section{References}

1. Brandenburg, K.: DIAMOND. Visual Crystal Structure Information System. Ver. 4.0. Crystal Impact, Bonn, Germany (2015).

2. Bruker. SAINT (Version 8.38A) in APEX3 (Version 2018.1-0). Bruker AXS Inc., Madison, WI, USA (2018).

3. Krause, L.; Herbst-Irmer, R.; Sheldrick, G. M.; Stalke, D.: Comparison of silver and molybdenum microfocus $\mathrm{X}$-ray sources for single crystal structure determination. J. Appl. Crystallogr. 48 (2015) 3-10.

4. Sheldrick, G. M.: Crystal structure refinement with SHELXL. Acta Crystallogr. C71 (2015) 3-8.

5. Reiss, G. J.; Meyer, M. K.: Diisopropylammonium methanesulfonate. Acta Crystallogr. E 67 (2011) 02169.

6. Debrus, S.; Marchewka, M. K.; Drozd, M.; Ratajczak, H.: Vibrational, calorimetric and nonlinear optical studies of melaminium bis(trichloroacetate) monohydrate molecularionic crystal. Opt. Mater. 29 (2007) 1058-1062.
7. Parsons, S.; Flack, H. D.; Wagner, T.: Use of intensity quotients and differences in absolute structure refinement. Acta Crystallogr. B69 (2013) 249-259.

8. Fu, D.-W.; Zhang, W.; Cai, H.-L.; Ge, J.-Z.; Zhang, Y.; Xiong, R.-G.: Diisopropylammonium chloride: a ferroelectric organic salt with a high phase transition temperature and practical utilization level of spontaneous polarization. Adv. Mater. 23 (2011) 5658-5662.

9. Louis, L.; Pitike, K. C.; Ghosh, A.; Poddar, S.; Ducharme, S.; Nakhmanson, S. M.: Polarization canting in ferroelectric diisopropylammonium-halide molecular crystals: a computational first principles study. J. Mater. Chem. C6 (2018) $1143-1152$.

10. Baryshnikov, S. V.; Charnaya, E. V.; Milinskiy, A. Y.; Parfenov, V. A.; Egorova, I. V.: Impact of nanoconfinement on the diisopropylammonium chloride $\left(\mathrm{C}_{6} \mathrm{H}_{16} \mathrm{CIN}\right)$ organic ferroelectric. Phase Trans. 91 (2018) 293-300.

11. Piecha, A.; Gagor, A.; Jakubas, R.; Szklarz, P.: Roomtemperature ferroelectricity in diisopropylammonium bromide. CrystEngComm 15 (2013) 940-944.

12. Piecha-Bisiorek, A.; Gągor, A.; Isakov, D.; Zieliński, P.; Gałązka, M.; Jakubas, R.: Phase sequence in diisopropylammonium iodide: avoided ferroelectricity by the appearance of a reconstructed phase. Inorg. Chem. Front. 4 (2017) 553-558.

13. Fu, D. W.; Cai, H. L.; Liu, Y.; Ye, Q.; Zhang, W.; Zhang, Y.; Chen, X. Y.; Giovannetti, G.; Capone, M.; Li, J.; Xiong, R. G.: Diisopropylammonium bromide is a high-temperature molecular ferroelectric crystal. Science 339 (2013) 425-428.

14. Jiang, C.; Tong, W.-Y.; Lin, H.; Luo, C.; Peng, H.; Duan, C.-G.: Effect of counter anions on ferroelectric properties of diisopropylammonium-cation based molecular crystals. Phys. Status Solidi 214 (2017) 1700029.

15. Gao, K.; Cui, Z.; Liu, C.; Zhu, J.; Cai, H.-L.; Wu, X.: Two reversible ferroelectric phase transitions in diisopropylammonium perchlorate. RSC Adv. 5 (2015) 62647-62651.

16. Zhou, P.; Sun, Z.; Zhang, S.; Ji, C.; Zhao, S.; Xiong, R.-G.; Luo, J.: A sequentially switchable molecular dielectric material tuned by the stepwise ordering in diisopropylammonium trifluoromethanesulfonate. J. Mater. Chem. C2 (2014) 2341-2345.

17. Bajorat, S.; Reiss, G. J.: Diisopropylammonium perchlorate at 263 K. Acta Crystallogr. E63 (2007) 03144.

18. Prince, P.; Miller, J. A.; Fronczek, F. R.; Gandour, R. D.: Diisopropylammonium chloride. Acta Crystallogr. C46 (1990) 336-338.

19. Reiss, G. J.: Diisopropylammonium hydrogen difluoride. Acta Crystallogr. C 57 (2001) 994-995.

20. Adams, C.; Raithby, P. R.; Davies, J. E.: Diisopropylammonium chloride. Private Communication to the CCDC (1997). Reference code: JAYPUU01, deposition no. 100996.

21. Kociok-Köhn, G.; Lungwitz, B.; Filippou, A. C.: Diisopropylammonium bromide. Acta Crystallogr. C52 (1996) 2309-2311.

22. Reiss, G. J.: Diisopropylammonium bromide. Private Communication to the CCDC (2010). Reference code: TEJKU003, deposition no. 770543.

23. Haberecht, M.; Lerner, H. W.; Bolte, M.: The low-temperature phase of diisopropylammonium bromide. Acta Crystallogr. C58 (2002) 0555-557. 
24. Reiss, G. J.: Diisopropylammonium iodide. Private Communication to the CCDC (2010). Reference code: UJOLIP, deposition no. 769746.

25. Saripalli, R. K.; Swain, D.; Prasad, S.; Nhalil, H.; Bhat, H. L.; Guru Row, T. N.; Elizabeth, S.: Observation of ferroelectric phase and large spontaneous electric polarization in organic salt of diisopropylammonium iodide. J. Appl. Phys. 121 (2017) 114101.

26. Reiss, G. J.; Koppelhuber-Bitschnau, B.: Diisopropylammonium chloride hemihydrate, a combined single-crystal and powder diffraction. Acta Crystallogr. E58 (2002) 01309-01311.

27. Nieger, M. M.; Niecke, E.; Loew, A.: Diisopropylammonium chloride trichloromethane solvate. Private Communication to the CCDC (1999). Reference code: HORVAL; deposition no. 117802.

28. Vitze, H.; Lerner, H.-W.; Bolte, M.: Di-isopropylammonium chloride chloroform solvate. Private Communication to the CCDC (2005). Reference code: HORVAL01; deposition no. 275730.

29. Reiss, G. J.; Meyer, M. K.: Synthesis and structural characterization of diisopropylammonium trifluoroacetate and diisopropylammonium pentafluoropropionate, Z. Naturforsch. B65 (2010) 479-484.

30. Reiss, G. J.: Bis(diisopropylammonium) hexafluorosilicate(IV). Acta Crystallogr. C54 (1998) 1489-1491.

31. Reiss, G. J.: The pseudosymmetric structure of bis(diisopropylammonium) hexachloroiridate(IV) and its relationship to potassium hexachloroiridate(III). Acta Crystallogr. E58 (2002) m47-m50.
32. Karuppasamy, P.; Senthil Pandian, M.; Ramasamy, P.; Das, S. K.: Growth and characterization of semi-organic nonlinear optical (NLO) guanidinium trichloroacetate (GTCA) single crystal. Optik 156 (2018) 707-719.

33. Dhanaraj, P. V.; Rajesh, N. P.; Vinitha, G.; Bhagavannarayana, G.: Crystal structure and characterization of a novel organic optical crystal: 2-Aminopyridinium trichloroacetate. Mater. Res. Bull. 46 (2011) 726-731.

34. Rekha, P.; Jayaprakash, P.; Rajasekar, G.; Mohan Kumar, R.; Vinitha, G.; Kanagadurai, R.: Synthesis, growth, structural and optical properties of a novel organic third order nonlinear optical crystal: Piperazinediium trichloroacetate. J. Mol. Struct. 1177 (2019) 579-593.

35. Reiss, G. J.; Meyer, M. K.: Diisopropylammonium trichloroacetate. Private Communication to the CCDC (2018). Reference code: BIWKOK, deposition no. 1883932.

36. Grell, J.; Bernstein, J.; Tinhofer, G.: Investigation of hydrogen bond patterns: a review of mathematical tools for the Graph Set approach. Crystallogr. Rev. 8 (2002) 1-56.

37. Förster, G.; Meister, A.; Blume, A.: Van der Waals energy contour map describing the orthorhombic hydrocarbon chain packing of symmetry Pbnm. Phys. Chem. Chem. Phys. 2 (2000) 4503-4508.

38. Wei, B.: Diisopropylammonium 4-methoxybenzoate. Acta Crystallogr. E67 (2011) 01865.

39. Sarr, B.; Diop, C. A. K.; Diop, L.; Blanchard, F.; Michaud, F.: Diisopropylammonium 4-aminobenzenesulfonate. IUCrData 1 (2016) x161545. 